\title{
Planned Randomization Book Allocation
}

National Cancer Institute

\section{Source}

National Cancer Institute. Planned Randomization Book Allocation. NCI Thesaurus. Code C93443.

An activity that is intended to occur at some point in the course of a particular study and that is the assignment of an experimental unit to a portion of the study, such as an arm or a portion of an arm (when secondary allocations may occur) based on a randomization book. 